\title{
Discharged from a mental health admission ward: is it safe to go home? A review on the negative outcomes of psychiatric hospitalization
}

This article was published in the following Dove Press journal:

Psychology Research and Behavior Management

28 April 2014

Number of times this article has been viewed

\author{
Alexandre Andrade Loch \\ Laboratory of Neurosciences, \\ Department and Institute of \\ Psychiatry, University of São Paulo, \\ Brazil
}

\begin{abstract}
Before psychiatry emerged as a medical discipline, hospitalizing individuals with mental disorders was more of a social stigmatizing act than a therapeutic act. After the birth of the mental health disciplines, psychiatric hospitalization was legitimized and has proven to be indispensable, preventing suicides and helping individuals in need. However, despite more than a century passing since this legitimization occurred, psychiatric hospitalization remains a controversial issue. There is the question of possible negative outcomes after a psychiatric admission ceases to take its protective effect, and even of whether the psychiatric admission itself is related to a negative setback after discharge. This review aims to summarize some of the most important negative outcomes after discharge from a psychiatric institution. These experiences were organized into two groups: those after a brief psychiatric hospitalization, and those after a long-stay admission. The author further suggests possible ways to minimize these adversities, emphasizing the need of awareness related to this important issue.
\end{abstract}

Keywords: suicide, stigma, rehabilitation, relapse, rehospitalization

\section{Introduction}

The mental health disciplines are unique in the field of medicine/health. One reason for this uniqueness is the fact that the object of study is the brain, the most important human organ, which must be understood in its complex hybrid social-biological framework. ${ }^{1}$ Another related issue that makes these disciplines distinctive relies on one of its main therapeutic interventions: psychiatric hospitalization.

It sounds odd when one says that a medical specialty is unique because of its procedure of admitting patients into a hospital for treatment purposes. Nevertheless, psychiatric hospitalization has always been a focus of controversy and endless debates. ${ }^{2}$ We should initially acknowledge that "hospitalizing" someone because of mental health problems has been practiced since the seventeenth century, ${ }^{2,3}$ a time before psychiatry or psychology were even born. That is also why hospitalizing is placed in quotation marks: at that time there was no solid concept of mental illness. Disturbed behavior and disordered mental functioning due to psychiatric or neurologic conditions were faced as cases of spiritual possession or moral deviation, for instance. ${ }^{3}$ Confining these patients in an institution was more of a stigmatizing social act than a health care act. According to Edward Shorter, ${ }^{3}$ it was only in the eighteenth to nineteenth century, when doctors acknowledged that hospitalization could have a therapeutic effect, that psychiatry emerged as a medical discipline. As a consequence, psychiatric institutions, which earlier had solely a custodial role, became true, psychiatric hospitals. Later on, 
besides the believed therapeutic effect of the hospitalization itself, these facilities became places for other medical interventions, such as therapeutic baths, insulin therapy, electroconvulsive therapy, etc.

Even though psychiatric facilities came to be places to treat instead of detain patients, the procedure of hospitalizing a mentally ill person was still being used in many cases with the purpose of discrimination. ${ }^{4}$ This was mainly reflected by the long-term admissions, in which many patients had lengths of stay exceeding 1 year. It was not until recently that the act of maintaining psychiatric patients for long periods in the hospital was questioned and changed by reforms in the way psychiatric assistance was delivered. ${ }^{5} \mathrm{In}$ the last few decades, a mental health care reform has had to be conducted worldwide to close long-stay hospitals and to change the paradigm of lengthy stays at an institution toward brief hospitalization and community-based treatment. In countries where this reform is still taking place, we can see the effect even today of the stigmatizing practice of isolating individuals from society for years, as these former long-stay patients return to society and experience tremendous difficulty in readapting themselves to society. ${ }^{6}$ So, psychiatric hospitalization mimics a social-biological framework in the sense that it can be seen as a legitimate biological-medical procedure, but it can also still reflect a social stigmatizing act, perpetuating an old heritage. ${ }^{?}$

Moreover, as a result of this enduring heritage, instead of being understood as a valid medical procedure, taking someone to a hospital because of disorders of the mind might sound to the patient (and to society) as a defeat, a failure, or a rejection of his/her behavior. ${ }^{8}$ And thus, returning to the community after a psychiatric admission can become a difficult task, due to the patient's misled feelings that he or she carries a "burden" of a previous psychiatric hospitalization.

To summarize, besides dealing with the fact that the procedure itself might be interpreted as stigmatizing, an ideal psychiatric admission must generally try to reach a delicate balance: a) it cannot last too long in case it stigmatizes the admitted patient by taking that person out of society for an extended period, but b) it cannot also be too brief otherwise the medical goals of the admission cannot be fulfilled and risk of relapse (eg, relapse of suicidal ideation or aggressive behavior) increases. In view of all these factors, there is a higher chance of the occurrence of negative outcomes after someone is discharged from a psychiatric hospitalization.

This review aims to analyze the possible negative outcomes following discharge from a psychiatric hospitalization. A search in PubMed for works published from 1980 onward, using the terms "psychiatric hospitalization" or "psychiatric admission" or "deinstitutionalization" and "outcome", returned 563 results. There was a remarkable paucity of data regarding the objective of the current project, and most studies were not relevant for the current work; thus 45 articles were included in this review. The selected works could be divided into two types: discharge after a long-stay psychiatric admission, and discharge after a brief psychiatric hospitalization. These will be analyzed separately.

\section{Negative outcomes after discharge from a brief psychiatric hospitalization}

The first and more obvious possible negative outcome after a psychiatric hospitalization is rehospitalization. A study conducted in Australia followed up 135 patients discharged from an acute psychiatric ward. ${ }^{9}$ They found a six-month rehospitalization rate of $38 \%$. Readmission was related to more psychiatric symptomatology and more disturbed behavior. A Brazilian study, conducted in São Paulo, the most populous metropolis of the country, also assessed rehospitalization rates among patients with psychotic and bipolar disorders. After 1 year of follow-up, the readmission rate of the sample was $43 \% .^{7}$ In the US 150 patients discharged from a psychiatric ward were also followed up for 1 year. Their rate of readmission was $30 \% .{ }^{10}$ Recent studies observed that early readmission rates, usually defined as occurring within 90 days of discharge, can be as high as $13 \%{ }^{11}$ Several factors were associated with readmission, but number of previous admissions seemed to be one of the most important predictors of readmission. ${ }^{7}$ This would fit with the theory of "revolving-door" patients. ${ }^{12}$ This theory states that a specific set of patients exhibit a pattern of high frequency of use of psychiatric beds. These could be the sort of subjects whose long-term stays at psychiatric institutions in earlier eras were substituted for multiple short hospitalizations. In short, considering that rehospitalization rates are high among psychiatric patients, one should acknowledge that the psychiatric ward can solve acute problems, but does not seem to be a solution for the underlying problem that generated the admission. Discharged patients would then sooner or later experience the same distress and symptoms that brought them to the index admission.

Since some authors argue that low use of depotantipsychotics and an earlier-than-necessary discharge from the hospital would contribute to the "revolving door" pattern, ${ }^{13}$ non-compliance would be one of the hypothetical problems underlying multiple readmissions. As such, 
Olfson et $\mathrm{al}^{14}$ observed that in individuals with schizophrenia the first weeks after discharge were especially vulnerable to medication noncompliance. This would be generated by the patient's greater autonomy and control over several aspects of their daily lives. Olfson et al assessed 316 inpatients in New York, and observed that approximately one in five patients reported missing 1 week or more of their oral medications during the first 3 months after hospital discharge. ${ }^{14}$ The authors noted that noncompliance, in its turn, was associated with several untoward outcomes, such as homelessness and rehospitalization. Substance use disorders emerged as the strongest predictor of noncompliance.

A disrupted family environment may also account for several factors that lead to hospitalization and re-hospitalization of the psychiatric patient. For example, Loch ${ }^{7}$ studied 169 patients with bipolar or psychotic disorder after their discharge from an acute psychiatric facility in Brazil. One-year rehospitalization rate was as high as $43 \%$. Even though several factors related to readmission were analyzed (such as non-compliance, disease severity, number of previous hospitalizations, etc), the highest predictor of re-hospitalization was familial stigma against the patient.

The second important negative outcome after discharge from a psychiatric unit is suicide. Suicide risk and suicide attempt are indicators of a need for hospitalization. Hospitalization can mitigate this risk, but since the majority of psychiatric disorders are chronic, patients can relapse from their suicidal ideations and kill themselves when not in hospital. Furthermore, Goldacre et a ${ }^{15}$ astutely observed that since psychiatric care has changed from a hospital-based to a community-centered model, risk of suicide in psychiatric patients has probably also shifted from the hospital to the community setting. These authors, concerned with cases of suicide soon after discharge, studied this occurrence during the first year after discharge from a psychiatric inpatient care. Reviewing a database of the Oxford Regional Health Authority area, they found 14,240 individuals aged 15 years and over who had a total of 26,864 admissions to psychiatric hospitals. Of those, $134(0.9 \%)$ died by suicide in the year following discharge. They found that the month after discharge is a time of particularly high risk. Specifically for men, the first day was the most crucial, with twice as high a risk of suicide compared to the rest of the month. This could be generated by perceived loss of support, reduced supervision, relapse because of renewed exposure to problems in the home environment, withdrawal of drug therapy, or the fact that the patient is still unwell. Risk of suicide seemed greater for patients with affective illness.
Regarding mortality after discharge, Sohlman and Lehtinen ${ }^{16}$ investigated this issue in former psychiatric inpatients in 1999. Several studies found that mortality among individuals with psychiatric diagnoses is higher than that among the general population. ${ }^{16}$ These rates vary across different diagnoses, with individuals with affective illness in general having a mortality rate twofold higher, and individuals with schizophrenia an up to five times higher mortality. ${ }^{16,17}$ Nevertheless, only a few studies have addressed this issue in an inpatient psychiatric population. Sohlman and Lehtinen ${ }^{16}$ studied 22,940 individuals discharged from psychiatric wards in 1988. They collected data regarding their health up to 1992. The most frequent diagnosis was of schizophrenia or delusional psychosis; slightly less than one third of the sample having those diagnoses. In the course of the 4- or 5-year follow-up period, 3,936 (17.2\%) patients died. The most common cause of death was suicide (17\%), followed by acute myocardial infarction (9.5\%), and pneumonia (6.7\%). Analyzing patients according to age strata, the authors observed that the standardized mortality rate of individuals $\leq 30$ years of age was 10 times higher than that of the general population. Also, half of these individuals died by suicide, and in total $90 \%$ died from unnatural causes (including accidents, for instance). Cardiovascular diseases were the most common cause of death for those over 45 years. Death was twice as likely in males. Individuals with psycho-organic disorders and substance use disorders were also at a higher risk.

We can consider the risk of violence as the third negative outcome related to individuals discharged from acute psychiatric units. Silver et a ${ }^{18}$ studied violence risk among persons discharged from a psychiatric hospital. They analyzed 293 subjects discharged from an acute psychiatric ward in Pittsburgh. In their sample the most frequent diagnosis was depression (47\%), followed by schizophrenia (15\%) and bipolar disorder (15\%). They observed that concentrated poverty in the neighborhoods in which patients resided after discharge significantly influenced the overall amount of violence they committed. The authors argued that in such neighborhoods, behaviors deemed as unacceptable or even criminal by the larger society might be more tolerable. Patients discharged into such settings might have been influenced by normative structures quite different from those in more affluent areas. Furthermore, these neighborhoods would present lower levels of social cohesion, meaning that behavior control is more difficult. As a consequence, patients discharged into these settings would be less constrained by informal mechanisms to conform to the norms and laws of the larger society. 
Some authors also believe that violence originated by patients who had been previously hospitalized is underestimated. Analyzing 7,740 discharged acute psychiatric patients from the eastern US states, Steadman et al, ${ }^{19}$ for instance, described that they would have reported a 1-year violence rate of $4.5 \%$ for those patients. Nevertheless, by using three independent information sources, they found a rate six times higher (27.5\%). Although this high rate was reported, a tendency to a decrease in those rates over time was also observed. The authors pointed out that the main factor associated with violence was the co-occurrence of substance abuse disorder. For patients without this comorbidity, rate of violence was $17.9 \%$, while the rate for those with the comorbidity was $31.1 \%{ }^{19}$ Thus, this study shows that patients discharged from acute psychiatric units are a heterogeneous group regarding violence. Most importantly, authors warn that public fears of violence on the street by discharged patients is misdirected; results showed that the highest risk group is family members and friends, who are in their own homes or in the patient's home.

\section{Long-stay psychiatric admission and deinstitutionalization}

Regarding the outcomes following a psychiatric hospitalization, another question that must be asked is: what is the fate of long-stay psychiatric patients who are deinstitutionalized?

An important issue is symptom change while patients undergo re-adaptation to society. Some might think that reinserting the patient into society, after so many years, might improve his/her symptoms. Leff and Trieman ${ }^{20}$ followed up long-stay psychiatric patients who were discharged after a hospital closure. Nearly half of the patients had been in hospital for more than 20 years. Of the 670 long-stay patients discharged into the community, 126 died in the first 5 years after discharge. Of the remaining, 97\% could be adequately followed up. Leff and Trieman concluded that patients were remarkably clinically stable across the time-span studied; as a whole, they neither presented improvement nor deterioration in symptoms, according to Present State Examination (PSE) scores. ${ }^{20}$ They also noted that negative symptoms and social functioning did not improve when patients were back in the community. Nevertheless, some sub-scores representing activities for which there is little or no opportunity in the hospital improved, especially in the first year after discharge. Quality of life also improved. Importantly, the authors noted that even patients with delusions and hallucinations are capable of acquiring skills useful for life in the community. ${ }^{20}$ On the contrary, Harding et a ${ }^{21}$ obtained somewhat different results.
They conducted a 32-year follow-up of 269 long-stay patients discharged in the 1950s in the USA. Seventy-nine percent had the diagnosis of schizophrenia according to Diagnostic and Statistical Manual of Mental Disorders, First Edition (DSM-I) while $13 \%$ were diagnosed as having affective disorders, and $8 \%$ as organic mental disorder. The analysis considered only individuals with schizophrenia; as such, only $54 \%(n=114)$ of those who were diagnosed as having schizophrenia at that time (DSM-I) retained the diagnosis with the DSM-III. Also, four patients were shifted from the affective illness group to the schizophrenia group, constituting an initial sample of 118 individuals with schizophrenia. Of those, 84 could be interviewed 20-25 years after their entry into the project. Sixtyeight percent of these patients did not display any further sign or symptoms of schizophrenia at follow-up; $45 \%$ displayed no psychiatric symptoms at all. The authors highlighted the importance of shifting perceptions about the proportion of individuals with schizophrenia who might achieve a better outcome than usually expected.

In line with Harding et al's findings,${ }^{21}$ a recent review carried out by Kunitoh ${ }^{6}$ analyzed the effect of deinstitutionalization on discharged long-stay psychiatric patients. Kunitoh found that for the most part, social functioning improved after discharge in the studies. A study specifically followed-up patients for 7-9 years and showed that they had higher scores in social functioning than the "controls" (inpatients who were not discharged). ${ }^{22,23}$ However, this outcome is by no means the rule, with some studies observing stability or even deterioration of social functioning. Kunitoh argued that this variability might be explained by the instruments used. ${ }^{6}$ Another important factor in explaining this variability is that some studies offered rehabilitation and social skills training for discharged patients, which might have resulted in better outcomes. Regarding symptoms, the author stated that the majority of studies point to a stability, confirming earlier findings. This would be in accordance with the fact that most long-term psychiatric patients have a diagnosis of schizophrenia and related disorders, and that these disorders usually present themselves with a plateau following a deterioration period. ${ }^{24}$

For those going home after so many years in an institution, suffering with the stigma of their mental illness is another persistent outcome. ${ }^{25,26}$ Once back in the community, patients experience new forms of rejection that tend to perpetrate internalized stigma acquired earlier in their lives and during institutionalization. Wright et $\mathrm{al}^{27}$ conducted a survey with long-term patients discharged from the Central State Hospital, IN, USA. They observed that stigma apparently persisted over time and contributed to the patient's 
decreasing feelings of mastery and control over their lives a year after discharge. Community-based care is often touted by mental health care reformers as a solution for the negative effects of deinstitutionalization, but it only has mild to modest effects. In other words, the social rejection exposure theory was confirmed, which states that persisting, stigmatizing beliefs held by society toward these individuals contribute to prejudiced experiences by psychiatric patients. ${ }^{26,28}$ These experiences tend to be internalized and serve to further increase stigma, decreasing self-esteem in a no-win situation pattern.

Another severe problem fueling stigma is the way in which deinstitutionalization occurs. As an example, we can cite the state of Massachusetts, USA. Massachusetts housed 23,000 persons in mental hospitals in the 1960s, but only 2000 by the mid-1980s. ${ }^{29}$ This quick deinstitutionalization led to a crisis of rampant unemployment, considerable homelessness, pervasive despair, and even noteworthy rates of premature deaths among the hundreds of thousands of deinstitutionalized across the nation. ${ }^{30}$ It was clear that, due to this abrupt shift from hospital to community-based care, lack of funding for community health care facilities occurred. This deficiency of assistance for psychiatric patients can be seen as a form of structural stigma against the mentally ill. ${ }^{31}$ As a consequence, this type of legislative handicap stimulates the vicious circle of stigma: patients get undertreated, symptoms are not controlled, negative views of the society are reinforced, and due to feelings of shame or helplessness patients refuse to seek help, further worsening their situation. ${ }^{32}$

Another consequence of clumsy psychiatric reform is rehospitalization. Continuing with the Massachusetts example, a 10 year follow-up revealed that $49 \%$ of long-stay patients were readmitted at least once. ${ }^{33}$ Figures rose up to $55 \%$ when a similar study was conducted in Chicago, but lower figures can also be found: for example, in New York (23\%) and Great Britain (27\%). ${ }^{33}$ Nevertheless, these rates are similar to those observed around the world, ${ }^{34,35}$ and represent quite a disappointing scenario in terms of a successful and effective shift toward community psychiatry, in the sense that a great number of individuals still need hospital-based assistance.

Considering other drawbacks of deinstitutionalization, could homelessness be another possible outcome for discharged long-stay psychiatric patients? An interesting study by Craig and Timms ${ }^{36}$ investigated mental health problems in Great Britain's homeless. Their findings were: mental illness was considerably higher among homeless when compared to the general population; the most frequent diagnosis was schizophrenia; and levels of disability were largely similar to the ones seen in long-stay psychiatric patients. Nevertheless, they found that most of these people did not have a history of previous long-term psychiatric hospitalization. Instead, they had several psychiatric admissions interspersed with periods of virtually no mental health assistance. The authors argued that hostels for homeless are probably not the home for discharged long-term patients. Instead, these institutions might constitute a niche for homeless people with mental disorders, where they can live with their symptoms with few getting annoyed with them, and with low social and work demands from society. Thus, in the past, two possible destinations for people with severe mental illness and low family support would have been possible: either they were institutionalized, or they lived like the homeless, with multiple brief psychiatric hospitalizations. Further reports reinforce that some percentage of the homeless have always been mentally ill, even before deinstitutionalizing practices took place. Considering this, a link between deinstitutionalization and homelessness cannot be made. ${ }^{37}$

Another possible undesirable outcome of deinstitutionalization stated in the literature might be increased rates of judicious problems concerning those getting out of long-term psychiatric facilities. ${ }^{38}$ There was an important debate in the USA on this issue, for example. ${ }^{39}$ Several studies observed that, before 1965, arrest rates due to violent crimes committed by psychiatric patients were lower than that of the general population.$^{40}$ However, after that year deinstitutionalization efforts were intensified in the country, and ex-institutionalized patients have had higher arrest rates..$^{40}$ Important factors might have accounted for this finding; the first of them is the fact that a great number of social disturbances caused by former patients were responded to by the police. Due to the lack of psychiatric beds at that time, bringing the ex-patient to an emergency unit would result in his/her rapid return to society. Thus, policemen felt that the most effective way to deal with these occurrences was to arrest the ex-patient rather than take them to hospital. ${ }^{40}$ The second factor concerns community mental health care facilities. It is recognized that many mental health care reforms lack an adequate number of outpatient services. The result is that many of these services become overloaded, and patients are frequently undertreated. Some also argue that at the time of the reform, many of these services were not equipped to face high-complexity patients such as those discharged from long-term hospitalization. Despite all these factors, a recent study found that crimes committed by individuals with schizophrenia during the period of deinstitutionalization, between 1975 and 1995, indeed increased in the USA. ${ }^{41}$ Nevertheless, the 
authors relativize this finding, observing that this increase was matched by a proportionately similar increase among community comparison subjects. ${ }^{40}$

\section{What can be done to reduce negative outcomes?}

If a psychiatric admission can prevent suicide or episodes of public or self-aggressiveness, for instance, discharge from a mental health inpatient service can put the affected individual back in his/her personal dysfunctional trajectory if no further intervention is conducted. In discharging patients from a psychiatric unit, it is also important to bear in mind that these persons were hospitalized for diseases that alter their behavior and mental states. Since a psychiatric ward is an artificial and controlled social setting, which might further disorder the patient's social codes of conduct, it is essential to provide them adequate social readaptation skills for the environment to which they will return. Moreover, specifically for patients with long-stays at the wards, the hospital's biased social interactions and routines must have substituted for the normal social codes learned from society, further increasing the difficulty in readaptation. As such, the in-patient to outpatient transition must be conducted in a very careful manner; it is clear that the period following hospitalization is crucial for individuals with mental disorders.

One important tool in providing a safer transition is psychoeducation. Psychoeducation might be an important factor in reducing setbacks after discharge. ${ }^{11}$ Family education proved to be useful in improving the social functioning of individuals with schizophrenia, ${ }^{42}$ while family and patient psychoeducation effectively reduced relapse rates in individuals with the disorder. ${ }^{43}$ Regarding individuals with bipolar disorder, psychoeducation had a positive impact in hospitalization rates, number of mood episodes, and time between episodes. ${ }^{44}$ Case-control studies show that this technique is useful for a wide range of diagnoses. ${ }^{45}$

Multicomponent interventions in this critical peridischarge period should also be employed. Pre-discharge medication education/reconciliation was found to diminish the risk of rehospitalization by one third ${ }^{45} \mathrm{~A}$ large body of evidence suggests that the delivery of ongoing communitybased care for patients who are at high risk of readmission further decreases their risk of going back to the hospital. ${ }^{45}$ This would include assertive community treatment and other forms of intensive care management. Post-discharge telephone follow-up, efforts to ensure timely follow-up appointments, and home visits would be other important allies in preventing readmission and relapse. ${ }^{11}$
As a consequence of the aforementioned issues, it is evident that community treatment services should be monitored and ameliorated if necessary. Since a shift from inpatient care toward community care has been accomplished, drastic closure of psychiatric beds and mental health policies' pressure to abbreviate acute hospitalizations might create an unanswered demand for hospitalizations. Yoon and Bruckner ${ }^{46}$ assessed variation in suicide rates in relation to psychiatric beds and community health spending in the US for the years 1982-1998. They found that supply of psychiatric beds was negatively associated with suicide rates: a decrease in one bed per 100,000 persons was associated with an increase of 0.025 suicides per 100,000 persons annually. The authors observed that from 1970 to 2000, psychiatric beds dropped from 207 to 21 beds per 100,000 persons ${ }^{47}$ This drastic reduction was not accompanied by a corresponding reduction in demand for those beds, or by a comparable investment in outpatient services, leading to lack of assistance and a possible rise in suicide rates. In Finland, on the other hand, an important focus on outpatient services and decentralized mental health care administration was carried out and the deinstitutionalization process was instead followed by a decrease in suicide rates. ${ }^{48}$

Community services are usually designed to shelter outpatients, that is, individuals with less severe mental illness. Nevertheless, they should also be able to receive patients egressed from psychiatric hospitals, who may present with increased symptom complexity and possibly a higher level of social disabilities as well. As such, special attention should be drawn to these individuals in outpatient settings, as they are undergoing the delicate process of being discharged from a psychiatric ward, reinserting themselves in community, and reawakening their societal roles.

Given these serious negative outcomes after discharge, one is led to wonder if acute psychiatric hospitalization should not last longer, to attempt to reduce these setbacks. Others argue that, besides these outlined negative outcomes, brief hospitalizations can produce the revolving door pattern, as already described. In other terms, brief hospitalizations would produce heavy users of acute psychiatric beds. ${ }^{50}$ However, there are currently several studies supporting the use of brief psychiatric admissions. ${ }^{50,51}$ As Frieri et al ${ }^{52}$ outline, psychiatric hospitalization should obey the following objectives: stabilizing symptoms; adjusting medication; and facilitating connections to outpatient care.

Finally, one important barrier for individuals with psychiatric disorders discharged from a psychiatric facility is stigma. It has already been observed that former inpatients are 
at special risk for discrimination. ${ }^{27}$ Furthermore, stigma has already been implicated in higher rates of rehospitalization, ${ }^{7}$ along with patients' failure to seek adequate treatment, ${ }^{53}$ low self-esteem, ${ }^{54}$ and lack of social adaptation. ${ }^{55}$ Consequently, fighting against society's stigma toward mental illness is central in reducing negative outcomes after discharge. Most importantly, the understanding that psychiatric hospitalization is a mental health care act and not an act of discrimination should be encouraged.

\section{Conclusion}

The fact that psychiatric hospitalization per se is an indispensable tool for managing some individuals with mental illness is unquestionable. Admission to a psychiatric ward can prevent deaths occasioned by suicide, ${ }^{56-58}$ help in the treatment of disorders that are typically difficult to manage, ${ }^{59}$ and improve functioning in various disorders. ${ }^{60}$ Nevertheless, there seems to be a gap in mental health care delivery after patients are discharged.

The current work focused on the negative outcomes after a psychiatric ward discharge, and found that there is a great level of distress in this critical period. If we sum the figures seen in this review, for example, at least half of these patients are rehospitalized or die by suicide in the long-term. Added to these two outcomes, violent behavior, social maladjustment, and stigma are other important negative setbacks after a psychiatric admission ceases to exert its protective effect. All of these outcomes seem to be more or less connected to a problematic transition from the hospital, where patients are fully assisted in all of their daily life aspects, to the community, where they must re-adapt to social roles and face the obstacle of an inhospitable society. If suicide or aggressive behavior can be prevented by admitting someone to a psychiatric ward, this prevention can also cease after discharge, and the odds of these events happening again can rise, probably due to low mental health care support at this outpatient stage.

The type of disorder psychiatric patients have invariably affects their behavior and social functioning, increasing stigma and the difficulty of social reintegration. A vicious cycle is then created, in which maladaptation exacerbates stigma, the affected person refrains from seeking help because of shame (or because of inadequate support), symptoms get worse, self-esteem decreases, and finally the negative outcomes mentioned before take place; relapse and rehospitalization.

Given this, it is of utmost importance that society, mental health professionals, and public policymakers become aware of this critical period post-discharge. Strategies to increase this awareness should be implemented, as well as intensification of assistance for those being discharged from a psychiatric ward.

There is one further factor leading to negative outcomes that we might say would be related to the psychiatric hospitalization itself: the discrimination related to this procedure. Since a previous psychiatric admission can generate an undeserved stigmatic burden, this idea should be banished by influencing society to have the right conceptions about mental illness and a correct understanding of the medical procedure of the psychiatric hospitalization.

Lastly, further studies should comprehensively assess this issue, for this is an under-researched subject in the international literature.

\section{Disclosure}

The author reports no conflicts of interest in this work.

\section{References}

1. Ghaemi SN. The Concepts of Psychiatry: A Pluralistic Approach to the Mind tnd Mental Illness. Baltimore: Johns Hopkins University Press; 2003.

2. Foucault M, Khalfa J. History of Madness. London; New York: Routledge; 2006.

3. Shorter E. A History of Psychiatry from the Era of the Asylum to the Age of Prozac. New York: John Wiley \& Sons; 1997.

4. Rüsch N, Corrigan PW, Wassel A, et al. Self-stigma, group identification, perceived legitimacy of discrimination and mental health service use. Br J Psychiatry. 2009;195(6):551-552.

5. Saxena S, Sharan P, Garrido M, Saraceno B. World Health Organization's Mental Health Atlas 2005: implications for policy development. World Psychiatry. 2006;5(3):179-184.

6. Kunitoh N. From hospital to the community: the influence of deinstitutionalization on discharged long-stay psychiatric patients. Psychiatry Clin Neurosci. 2013;67(6):384-396.

7. Loch AA. Stigma and higher rates of psychiatric re-hospitalization: São Paulo public mental health system. Rev Bras Psiquiatr. 2012;34(2): 185-192.

8. Angermeyer MC, Link BG, Majcher-Angermeyer A. Stigma perceived by patients attending modern treatment settings. Some unanticipated effects of community psychiatry reforms. J Nerv Ment Dis. 1987;175(1): 4-11.

9. Owen C, Rutherford V, Jones M, Tennant C, Smallman A. Psychiatric rehospitalization following hospital discharge. Community Ment Health J. 1997;33(1):13-24.

10. Schmutte T, Dunn CL, Sledge WH. Predicting time to readmission in patients with recent histories of recurrent psychiatric hospitalization: a matched-control survival analysis. J Nerv Ment Dis. 2010;198(12): 860-863.

11. Vigod SN, Kurdyak PA, Dennis CL, et al. Transitional interventions to reduce early psychiatric readmissions in adults: systematic review. Br J Psychiatry. 2013;202(3):187-194.

12. Haywood TW, Kravitz HM, Grossman LS, Cavanaugh JL Jr, Davis JM, Lewis DA. Predicting the "revolving door" phenomenon among patients with schizophrenic, schizoaffective, and affective disorders. Am J Psychiatry. 1995;152(6):856-861.

13. Botha UA, Koen L, Joska JA, et al. The revolving door phenomenon in psychiatry: comparing low-frequency and high-frequency users of psychiatric inpatient services in a developing country. Soc Psychiatry Psychiatr Epidemiol. 2010;45(4):461-468. 
14. Olfson M, Mechanic D, Hansell S, Boyer CA, Walkup J, Weiden PJ. Predicting medication noncompliance after hospital discharge among patients with schizophrenia. Psychiatr Serv. 2000;51(2):216-222.

15. Goldacre M, Seagroatt V, Hawton K. Suicide after discharge from psychiatric inpatient care. Lancet. 1993;342(8866):283-286.

16. Sohlman B, Lehtinen V. Mortality among discharged psychiatric patients in Finland. Acta Psychiatr Scand. 1999;99(2):102-109.

17. Saku M, Tokudome S, Ikeda M, et al. Mortality in psychiatric patients, with a specific focus on cancer mortality associated with schizophrenia. Int J Epidemiol. 1995;24(2):366-372.

18. Silver E, Mulvey EP, Monahan J. Assessing violence risk among discharged psychiatric patients: toward an ecological approach. Law Hum Behav. 1999;23(2):237-255.

19. Steadman HJ, Mulvey EP, Monahan J, et al. Violence by people discharged from acute psychiatric inpatient facilities and by others in the same neighborhoods. Arch Gen Psychiatry. 1998;55(5):393-401.

20. Leff J, Trieman N. Long-stay patients discharged from psychiatric hospitals. Social and clinical outcomes after five years in the community. The TAPS Project 46. Br J Psychiatry. 2000;176:217-223.

21. Harding CM, Brooks GW, Ashikaga T, Strauss JS, Breier A. The Vermont longitudinal study of persons with severe mental illness, II: Long-term outcome of subjects who retrospectively met DSM-III criteria for schizophrenia. Am J Psychiatry. 1987;144(6):727-735.

22. Lesage AD, Morissette R, Fortier L, Reinharz D, Contandriopoulos AP. Downsizing psychiatric hospitals: needs for care and services of current and discharged long-stay inpatients. Can J Psychiatry. 2000;45(6): 526-532.

23. Reinharz D, Lesage AD, Contandriopoulos AP. Cost-effectiveness analysis of psychiatric deinstitutionalization. Can J Psychiatry. 2000;45(6):533-538.

24. Abrahamson D. Institutionalisation and the long-term course of schizophrenia. Br J Psychiatry. 1993;162:533-538.

25. Loch AA, Guarniero FB, Lawson FL, et al. Stigma toward schizophrenia: do all psychiatrists behave the same? Latent profile analysis of a national sample of psychiatrists in Brazil. BMC Psychiatry. 2013;13:92.

26. Loch AA, Wang YP, Guarniero FB, et al. Patterns of stigma toward schizophrenia among the general population: A latent profile analysis. Int J Soc Psychiatry. Epub 2013 Oct 21.

27. Wright ER, Gronfein WP, Owens TJ. Deinstitutionalization, social rejection, and the self-esteem of former mental patients. J Health Soc Behav. 2000;41(1):68-90.

28. Loch AA, Hengartner MP, Guarniero FB, et al. Psychiatrists' stigma towards individuals with schizophrenia. Rev Psiquiatr Clin. 2011;38(5): 173-177.

29. Farina A, Fisher JD, Fisher EH. Societal factors in the problems faced by deinstitutionalized psychiatric patients. In: Fink PJ, Tasman A, editors. Stigma and Mental illness. Washington DC: American Psychiatric Press; 1992. p. 167-184.

30. Hinshaw SP, Cicchetti D. Stigma and mental disorder: Conceptions of illness, public attitudes, personal disclosure, and social policy. Development and Psychopathology. 2000;12(4):555-598.

31. Corrigan PW, Watson AC, Heyrman ML, et al. Structural stigma in state legislation. Psychiatr Serv. 2005;56(5):557-563.

32. Hinshaw SP. The Mark of Shame Stigma of Mental Illness and an Agenda for Change. Oxford; New York: Oxford University Press; 2007.

33. Thornicroft G, Gooch C, Dayson D. The TAPS project. 17: Readmission to hospital for long term psychiatric patients after discharge to the community. BMJ. 1992;305(6860):996-998.

34. Klinkenberg WD, Calsyn RJ. Predictors of receipt of aftercare and recidivism among persons with severe mental illness: a review. Psychiatr Serv. 1996;47(5):487-496.

35. Thompson EE, Neighbors HW, Munday C, Trierweiler S. Length of stay, referral to aftercare, and rehospitalization among psychiatric inpatients. Psychiatr Serv. 2003;54(9):1271-1276.

36. Craig T, Timms PW. Out of the wards and onto the streets? Deinstitutionalization and homelessness in Britain. J Ment Health. 1992;1(3):265.
37. Perlin ML. Competency, Deinstitutionalization, and Homelessness: A Story of Marginalization. Hous L Rev. 1991;63(1):64-116.

38. Whitmer GE. From hospitals to jails: the fate of California's deinstitutionalized mentally ill. Am J Orthopsychiatry. 1980;50(1):65-75.

39. Steadman HJ, Monahan J, Duffee B, Hartstone E, Robbins PC. The Impact of State Mental Hospital Deinstitutionalization on United States Prison Populations, 1968-1978. J Crim Law Criminol. 1984;75(2):474-490.

40. Pogrebin MR, Poole ED. Deinstitutionalization and increased arrest rates among the mentally disordered. J Psychiatry Law. 1987:117-127.

41. Wallace C, Mullen PE, Burgess P. Criminal offending in schizophrenia over a 25-year period marked by deinstitutionalization and increasing prevalence of comorbid substance use disorders. Am J Psychiatry. 2004;161(4):716-727.

42. Magliano L, Fiorillo A, Malangone C, De Rosa C, Maj M. Patient functioning and family burden in a controlled, real-world trial of family psychoeducation for schizophrenia. Psychiatr Serv. 2006;57(12): 1784-1791.

43. Cohen AN, Glynn SM, Murray-Swank AB, et al. The family forum: directions for the implementation of family psychoeducation for severe mental illness. Psychiatr Serv. 2008;59(1):40-48.

44. Vieta E, Rosa AR. Evolving trends in the long-term treatment of bipolar disorder. World J Biol Psychiatry. 2007;8(1):4-11.

45. Steffen S, Kösters M, Becker T, Puschner B. Discharge planning in mental health care: a systematic review of the recent literature. Acta Psychiatr Scand. 2009;120(1):1-9.

46. Yoon J, Bruckner TA. Does deinstitutionalization increase suicide? Health Serv Res. 2009;44(4):1385-1405.

47. Manderscheid RW, Henderson MJ. Mental health, United States, 2002 Executive Summary. Adm Policy Ment Health. 2004;32(1):49-55.

48. Pirkola S, Sohlman B, Heilä H, Wahlbeck K. Reductions in postdischarge suicide after deinstitutionalization and decentralization: a nationwide register study in Finland. Psychiatr Serv. 2007;58(2):221-226.

49. Harrison-Read P, Lucas B, Tyrer P, et al. Heavy users of acute psychiatric beds: randomized controlled trial of enhanced community management in an outer London borough. Psychol Med. 2002;32(3):403-416.

50. Lieberman PB, Strauss JS. Brief psychiatric hospitalization: what are its effects? Am J Psychiatry. 1986;143(12):1557-1562.

51. Mok H, Watler C. Brief psychiatric hospitalization: preliminary experience with an urban short-stay unit. Can J Psychiatry. 1995;40(7):415-417.

52. Frieri T, Montemagni C, Rocca G, Rocca P, Villari V. Clinical outcome and length of stay in an Italian Psychiatric Emergency Service. Soc Psychiatry Psychiatr Epidemiol. 2013;48(6):1013-1020.

53. Corrigan P. How stigma interferes with mental health care. Am Psychol. 2004;59(7):614-625

54. Link BG, Struening EL, Neese-Todd S, Asmussen S, Phelan JC. Stigma as a barrier to recovery: The consequences of stigma for the self-esteem of people with mental illnesses. Psychiatr Serv. 2001;52(12):1621-1626.

55. Perlick DA, Rosenheck RA, Clarkin JF, et al. Stigma as a barrier to recovery: Adverse effects of perceived stigma on social adaptation of persons diagnosed with bipolar affective disorder. Psychiatr Serv. 2001;52(12):1627-1632.

56. Cornelius JR, Clark DB, Salloum IM, Bukstein OG, Kelly TM. Interventions in suicidal alcoholics. Alcohol Clin Exp Res. 2004;28 (5 Suppl):89S-96S.

57. Zametkin AJ, Alter MR, Yemini T. Suicide in teenagers: assessment, management, and prevention. JAMA. 2001;286(24):3120-3125.

58. Greenhill LL, Waslick B. Management of suicidal behavior in children and adolescents. Psychiatr Clin North Am. 1997;20(3):641-666.

59. Bateman A, Fonagy P. Effectiveness of partial hospitalization in the treatment of borderline personality disorder: a randomized controlled trial. Am J Psychiatry. 1999;156(10):1563-1569.

60. Rabinowitz J, Modai I, Inbar-Saban N. Understanding who improves after psychiatric hospitalization. Acta Psychiatr Scand. 1994;89(3):152-158. 
Psychology Research and Behavior Management

Dovepress

\section{Publish your work in this journal}

Psychology Research and Behavior Management is an international, peerreviewed, open access journal focusing on the science of psychology and its application in behavior management to develop improved outcomes in the clinical, educational, sports and business arenas. Specific topics covered include: Neuroscience, memory \& decision making; Behavior modification \& management; Clinical applications; Business \& sports performance management; Social and developmental studies; Animal studies. The manuscript management system is completely online and includes a quick and fair peer-review system. Visit http://www.dovepress. com/testimonials.php to read real quotes from published authors.

Submit your manuscript here: http://www.dovepress.com/psychology-research-and-behavior-management-journal 